\title{
Chitosan as a Renewable Heterogeneous Catalyst for the Knoevenagel Reaction in Ionic Liquid as Green Solvent
}

\author{
Nam T. S. Phan, Ky K. A. Le, Thien V. Nguyen, and Nhan T. H. Le \\ Department of Chemical Engineering, Ho Chi Minh City University of Technology, VNU-HCM, \\ 268 Ly Thuong Kiet, District 10, Ho Chi Minh City 70350, Vietnam \\ Correspondence should be addressed to Nam T. S. Phan, ptsnam@hcmut.edu.vn
}

Received 3 April 2012; Accepted 14 June 2012

Academic Editors: D. Chaturvedi, F. D’Anna, J. R. Hwu, and L. Novak

Copyright ( $\odot 2012$ Nam T. S. Phan et al. This is an open access article distributed under the Creative Commons Attribution License, which permits unrestricted use, distribution, and reproduction in any medium, provided the original work is properly cited.

\begin{abstract}
The combination of chitosan as a renewable heterogeneous catalyst and ionic liquid as a "green" solvent was employed for the Knoevenagel reaction. The chitosan catalyst was characterized by various techniques, including X-ray powder diffraction (XRD), scanning electron microscopy (SEM), transmission electron microscopy (TEM), thermogravimetric analysis (TGA), Fourier transform infrared spectroscopy (FT-IR), and elemental analysis. Excellent conversions were achieved under mild conditions without the need for an inert atmosphere. There was no contribution from leached active species, and conversion was only being possible in the presence of the solid catalyst. The chitosan catalyst as well as the ionic liquid solvent could be recovered in essentially pure form after being used in the reaction, and each of them could be reused several times without a significant degradation in efficiency.
\end{abstract}

\section{Introduction}

Room temperature ionic liquids have been considered as potential green alternatives to conventional volatile organic solvents during the last decade [1-5]. They exhibit several advantages such as negligible vapor pressure, excellent ability to dissolve organic compounds, ease of separation from products, and potential for recycling [6-8]. A variety of ionic liquids have been investigated, generally consisting of salts of organic cations, for example, tetraalkylammonium, alkylpyridinium, 1,3-dialkylimidazolium, tetraalkylphosphonium $[2,9]$. During the past few years, several organic transformations have been carried out using ionic liquids as environmentally benign solvents, such as hydrogenation [10], oxidation [11-14], Heck cross-coupling reaction $[15,16]$, Suzuki reaction [17], Sonogashira reaction [18], Diels-Alder reaction [19], aldol condensation [20], alkylation [21-23], Micheal addition [24], oxa-Michael addition [25], Schmidt reaction [26], ring-closing metathesis [27], esterification reaction [28, 29], and enzyme-catalyzed organic reactions [30-33]. However, since the application of the first ionic liquid sample as solvent for organic transformations, research works have been mostly focused on homogeneous catalysis in ionic liquids. Indeed, reports on organic reactions using heterogeneous catalysts in ionic liquids as solvents have been very limited in the literature [34-38].

The Knoevenagel condensation between aldehydes or ketones with activated methylene compounds is one of important carbon-carbon forming reactions in organic synthesis $[39,40]$. Conventionally, this reaction is catalyzed by alkali metal hydroxides or by organic bases under homogeneous conditions with the attendant difficulties in catalyst recovery and recycling [41]. Over the last few years, several solid catalysts have been employed for this reaction such as zeolites exchanged with alkylammonium cations [42], amine-functionalized mesoporous zirconia [43], mesoporous titanosilicate [44], basic MCM-41 silica [45-47], acid-base bifunctional mesoporous MCM-41 silica [48], nanocrytalline ceria-zirconia [49], amine-functionalized superparamagnetic nanoparticles [50], organic-inorganic hybrid silica materials [51], and metal-organic frameworks $[52,53]$. Chitosan, a biomaterial derived from crustacean shells, offers the advantages of being renewable and biodegradable, as well as being relatively cheap and of low toxicity [54]. It was used as a "green" catalyst support for several 
transitional metal-catalyzed reactions [55-58], and it was also used as a solid base catalyst for the aldol condensation reaction [59]. However, all of these processes were still carried out in conventional volatile organic solvents. In this paper, we wish to report the combination of chitosan as a renewable heterogeneous catalyst and ionic liquid as a green solvent for the Knoevenagel reaction. The chitosan catalyst as well as the ionic liquid solvent could be recovered in essentially pure form after being used in the reaction. Both the catalyst and the solvent could be reused several times without a significant degradation in performance.

\section{Experimental}

2.1. Materials and Instrumentation. All reagents and starting materials were obtained commercially from Sigma-Aldrich and Merck, and they were used as received without any further purification unless, otherwise, noted. Chitosan was kindly donated by MKVN Chemicals Company (authorized distributor of COGNIS-HENKEL, Germany). Nitrogen physisorption measurements were conducted using a Quantachrome 2200e system. Samples were pretreated by heating under vacuum at $150^{\circ} \mathrm{C}$ for $3 \mathrm{~h}$. A Netzsch Thermoanalyzer STA 409 was used for thermogravimetric analysis (TGA) with a heating rate of $10^{\circ} \mathrm{C} / \mathrm{min}$ from 30 to $900^{\circ} \mathrm{C}$ in air. Xray powder diffraction (XRD) patterns were recorded using a $\mathrm{Cu} \mathrm{K} \alpha$ radiation source on a D8 Advance Bruker powder diffractometer. Scanning electron microscopy studies were conducted on a JSM 740 Scanning Electron Microscope (SEM). Transmission electron microscopy studies were performed using a JEOL JEM 1400 Transmission Electron Microscope (TEM) at $100 \mathrm{kV}$. The chitosan samples were dispersed on holey carbon grids for TEM observation. Fourier transform infrared (FT-IR) spectra were obtained on a Bruker TENSOR37 instrument, with samples being dispersed on potassium bromide pallets. ${ }^{1} \mathrm{H}$ and ${ }^{13} \mathrm{C}$ NMR spectra were recorded using a Bruker AV 500 spectrometer. MS spectra were performed on a Thermo Finigan TSQ7000 triple quadrupole.

Gas chromatographic (GC) analyses were performed using a Shimadzu GC 17-A equipped with a flame ionization detector (FID) and an DB-5 column (length $=30 \mathrm{~m}$, inner diameter $=0.25 \mathrm{~mm}$, and film thickness $=0.25 \mu \mathrm{m})$. The temperature program for GC analysis heated samples from 60 to $200^{\circ} \mathrm{C}$ at $20^{\circ} \mathrm{C} / \mathrm{min}$ and held them at $150^{\circ} \mathrm{C}$ for $1 \mathrm{~min}$; then heated them from 150 to $160^{\circ} \mathrm{C}$ at $1^{\circ} \mathrm{C} / \mathrm{min}$ and held them at $200^{\circ} \mathrm{C}$ for $2 \mathrm{~min}$; then heated them from 200 to $300^{\circ} \mathrm{C}$ at $50^{\circ} \mathrm{C} / \mathrm{min}$ and held them at $300^{\circ} \mathrm{C}$ for $4 \mathrm{~min}$. Inlet and detector temperatures were set constant at $300^{\circ} \mathrm{C}$. $p$-Xylene was used as an internal standard to calculate reaction conversions. GC-MS analyses were performed using a Hewlett Packard GC-MS 5972 with an RTX-5MS column (length $=30 \mathrm{~m}$, inner diameter $=0.25 \mathrm{~mm}$, and film thickness $=0.5 \mu \mathrm{m})$. The temperature program for GC-MS analysis heated samples from 60 to $280^{\circ} \mathrm{C}$ at $10^{\circ} \mathrm{C} / \mathrm{min}$ and held them at $280^{\circ} \mathrm{C}$ for $2 \mathrm{~min}$. Inlet temperature was set constant at $280^{\circ} \mathrm{C}$. MS spectra were compared with the spectra gathered in the NIST library.
2.2. Synthesis of Ionic Liquid. 1-Butyl-3-methylimidazolium bromide ([BMIM][Br]) was prepared from the reaction of $N$-methylimidazole and $n$-butyl bromide, according to a literature procedure $[60,61]$. A plastic conical flask containing a mixture of [BMIM] [Br] $(25.10 \mathrm{~g}, 0.115 \mathrm{~mol})$ and distilled water $(50 \mathrm{~mL})$ was immersed in an ice bath for $30 \mathrm{~min}$. Hexafluorophosphoric acid $\left(\mathrm{HPF}_{6}\right) 60 \%(20 \mathrm{~mL}$, $0.147 \mathrm{~mol}$ ) and water $(50 \mathrm{~mL})$ were then added dropwise to prevent the temperature from rising significantly. After stirring for $12 \mathrm{~h}$ at room temperature, the upper acidic aqueous layer was separated by decantation and the lower ionic liquid phase was washed with cold water $(10 \times 50 \mathrm{~mL})$ until the washings were no longer acidic [61]. The ionic liquid was then heated under vacuum at $60^{\circ} \mathrm{C}$ to remove any excess water, affording $27.32 \mathrm{~g}$ of 1-butyl-3-methylimidazolium hexafluorophosphate ([BMIM] $\left.\left[\mathrm{PF}_{6}\right]\right)$ (83\% yield).

${ }^{1} \mathrm{H}$ NMR (500 MHz, DMSO-d6): $\delta=0.91\left(\mathrm{t}, 3 \mathrm{H} ; \mathrm{CH}_{3}\right.$ ), 1.26 (m, 2H; $\left.\mathrm{CH}_{2} \mathrm{CH}_{3}\right), 1.77\left(\mathrm{~m}, 2 \mathrm{H} ; \mathrm{CH}_{2} \mathrm{CH}_{2} \mathrm{CH}_{3}\right), 3.85$ (s, $\left.3 \mathrm{H} ; \mathrm{N}-\mathrm{CH}_{3}\right), 4.16\left(\mathrm{~m}, 2 \mathrm{H} ; \mathrm{N}-\mathrm{CH}_{2}\right), 7.67$ (t, $\left.1 \mathrm{H} ; \mathrm{N}-\mathrm{CH}=\mathrm{C}\right)$, $7.73(\mathrm{t}, 1 \mathrm{H} ; \mathrm{N}-\mathrm{CH}=\mathrm{C}), 9.07(\mathrm{~s}, 1 \mathrm{H}, \mathrm{N}-\mathrm{CH}=\mathrm{N}) .{ }^{13} \mathrm{C} \mathrm{NMR}$ $(125 \mathrm{MHz}, \mathrm{DMSO}-\mathrm{d} 6): \delta=13.14\left(\mathrm{C}-\mathrm{CH}_{3}\right), 18.71\left(\mathrm{CH}_{2}\right)$, $31.27\left(\mathrm{CH}_{2}\right), 35.65\left(\mathrm{~N}-\mathrm{CH}_{3}\right), 48.51\left(\mathrm{~N}-\mathrm{CH}_{2}\right), 122.19(\mathrm{C}=\mathrm{C}-$ $\mathrm{N}), 123.54(\mathrm{C}=\mathrm{C}-\mathrm{N}), 136.44(\mathrm{~N}-\mathrm{C}=\mathrm{N})$. MS (ESI): $m / z 139$ $[\mathrm{BMIM}]^{+}, 423\left[(\mathrm{BMIM})_{2} \mathrm{PF}_{6}\right]^{+}$.

Using a similar procedure, 1-hexyl-3-methylimidazolium hexafluorophosphate ([HMIM] $\left.\left[\mathrm{PF}_{6}\right]\right)$, and 1-octyl-3-methylimidazolium hexafluorophosphate $\left([\mathrm{OMIM}]\left[\mathrm{PF}_{6}\right]\right)$ ionic liquids were synthesized in a yield of $83 \%$ and $85 \%$, respectively.

${ }^{1} \mathrm{H}$ NMR (500 MHz, DMSO-d6) for [HMIM] $\left[\mathrm{PF}_{6}\right]: \delta=$ $0.87\left(\mathrm{t}, 3 \mathrm{H} ; \mathrm{CH}_{3}\right), 1.27\left(\mathrm{~m}, 6 \mathrm{H} ; \mathrm{CH}_{2} \mathrm{CH}_{2} \mathrm{CH}_{2}\right), 1.78(\mathrm{~m}$, $\left.2 \mathrm{H} ; \mathrm{CH}_{2}\right), 3.85\left(\mathrm{~s}, 3 \mathrm{H} ; \mathrm{N}-\mathrm{CH}_{3}\right), 4.15\left(\mathrm{~m}, 2 \mathrm{H} ; \mathrm{N}-\mathrm{CH}_{2}\right)$, $7.77(\mathrm{t}, 1 \mathrm{H} ; \mathrm{N}-\mathrm{CH}=\mathrm{C}), 7.73(\mathrm{t}, 1 \mathrm{H} ; \mathrm{N}-\mathrm{CH}=\mathrm{C}), 9.07(\mathrm{~s}$, $1 \mathrm{H}, \mathrm{N}-\mathrm{CH}=\mathrm{N}) .{ }^{13} \mathrm{C}$ NMR $(125 \mathrm{MHz}, \mathrm{DMSO}-\mathrm{d} 6): \delta=13.71$ $\left(\mathrm{C}-\mathrm{CH}_{3}\right), 21.80\left(\mathrm{CH}_{2}\right), 25.09\left(\mathrm{CH}_{2}\right), 29.27\left(\mathrm{CH}_{2}\right), 30.49$ $\left(\mathrm{CH}_{2}\right), 35.65\left(\mathrm{~N}-\mathrm{CH}_{3}\right), 48.79\left(\mathrm{~N}-\mathrm{CH}_{2}\right), 122.19(\mathrm{C}=\mathrm{C}-\mathrm{N})$, $123.54(\mathrm{C}=\mathrm{C}-\mathrm{N}), 136.43(\mathrm{~N}-\mathrm{C}=\mathrm{N})$. MS (ESI): $\mathrm{m} / z(\%) 167$ $[\mathrm{HMIM}]^{+}, 479\left[(\mathrm{HMIM})_{2} \mathrm{PF}_{6}\right]^{+}$.

${ }^{1} \mathrm{H}$ NMR (500 MHz, DMSO-d6) for [OMIM] $\left[\mathrm{PF}_{6}\right]: \delta=$ 0.86 (t, 3H; $\mathrm{CH}_{3}$ ), 1.27 ( $\mathrm{m}, 10 \mathrm{H} ; \mathrm{CH}_{2} \mathrm{CH}_{2} \mathrm{CH}_{2} \mathrm{CH}_{2} \mathrm{CH}_{2}$ ), $1.78\left(\mathrm{~m}, 2 \mathrm{H} ; \mathrm{CH}_{2}\right), 3.85\left(\mathrm{~s}, 3 \mathrm{H} ; \mathrm{N}-\mathrm{CH}_{3}\right), 4.15(\mathrm{~m}, 2 \mathrm{H} ; \mathrm{N}-$ $\left.\mathrm{CH}_{2}\right), 7.67(\mathrm{t}, 1 \mathrm{H} ; \mathrm{N}-\mathrm{CH}=\mathrm{C}), 7.74(\mathrm{t}, 1 \mathrm{H} ; \mathrm{N}-\mathrm{CH}=\mathrm{C}), 9.08(\mathrm{~s}$, $1 \mathrm{H}, \mathrm{N}-\mathrm{CH}=\mathrm{N}) \cdot{ }^{13} \mathrm{C}$ NMR $(125 \mathrm{MHz}, \mathrm{DMSO}-\mathrm{d} 6): \delta=13.87$ $\left(\mathrm{C}-\mathrm{CH}_{3}\right), 22.39\left(\mathrm{CH}_{2}\right), 26.09\left(\mathrm{CH}_{2}\right), 28.77\left(\mathrm{CH}_{2}\right), 28.84$ $\left(\mathrm{CH}_{2}\right), 30.14\left(\mathrm{CH}_{2}\right), 31.50\left(\mathrm{CH}_{2}\right), 36.64\left(\mathrm{~N}-\mathrm{CH}_{3}\right), 50.00(\mathrm{~N}-$ $\left.\mathrm{CH}_{2}\right), 121.86(\mathrm{C}=\mathrm{C}-\mathrm{N}), 123.64(\mathrm{C}=\mathrm{C}-\mathrm{N}), 137.08(\mathrm{~N}-\mathrm{C}=\mathrm{N})$.

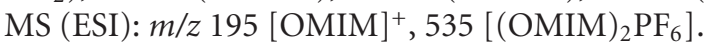

2.3. Catalytic Studies. The Knoevenagel reaction between benzaldehyde and malononitrile using the chitosan catalyst was carried out in a magnetically stirred round bottom flask. Unless, otherwise, stated, a mixture of chitosan (91 mg g, $20 \mathrm{~mol} \%)$, benzaldehyde $(0.2 \mathrm{~mL}, 1.9 \mathrm{mmol})$, and $p$-xylene $(0.2 \mathrm{~mL})$ as an internal standard was placed into a $25 \mathrm{~mL}$ flask containing $3 \mathrm{~mL}$ [BMIM] $\left[\mathrm{PF}_{6}\right]$. The catalyst concentration was calculated with respect to the amino/benzaldehyde molar ratio. The reaction vessel was stirred for $30 \mathrm{~min}$ to disperse the chitosan catalyst in the liquid phase. Malononitrile 


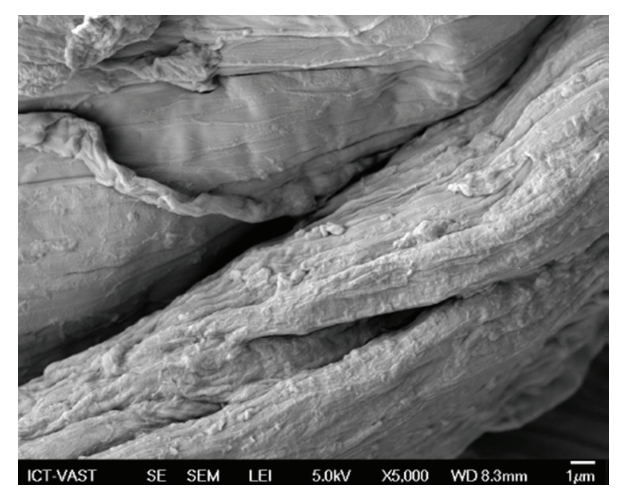

FIGURE 1: SEM micrograph of the chitosan catalyst.

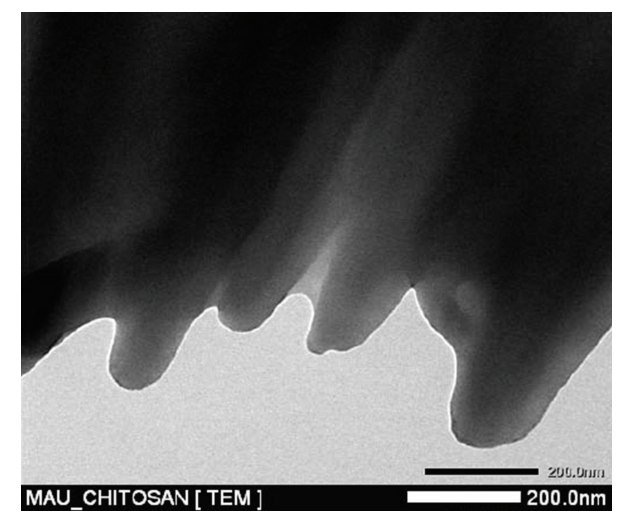

FIgURE 2: TEM micrograph of the chitosan catalyst.

$(0.5 \mathrm{~mL}, 7.6 \mathrm{mmol})$ was then added, and the resulting mixture was stirred at room temperature for $6 \mathrm{~h}$. Reaction conversion was monitored by withdrawing aliquots from the reaction mixture at different time intervals, quenching with acetone, filtering through a short silica gel pad, analyzing by GC with reference to $p$-xylene, and further confirming product identity by GC-MS. The reaction mixture was washed with diethyl ether $(5 \times 15 \mathrm{~mL})$. The chitosan catalyst was then separated by simple centrifugation, washed with copious amounts of anhydrous ethanol, dried at $60^{\circ} \mathrm{C}$ overnight, and reused if necessary. For the leaching test, a catalytic reaction was stopped after $0.5 \mathrm{~h}$, analyzed by GC, and centrifuged to remove the solid catalyst. The reaction solution was then stirred for further $5.5 \mathrm{~h}$ at room temperature. Reaction progress, if any, was monitored by GC as previously described.

\section{Results and Discussion}

3.1. Catalyst Characterization. The chitosan catalyst was characterized using a variety of different techniques, including SEM, TEM, XRD, FT-IR, TGA, nitrogen physisorption measurements, and elemental analysis. The morphology of the chitosan was observed from the SEM micrograph, exhibiting an uneven surface with straps and shrinkage (Figure 1). As expected, the TEM micrograph revealed that the chitosan catalyst possessed a nonporous structure

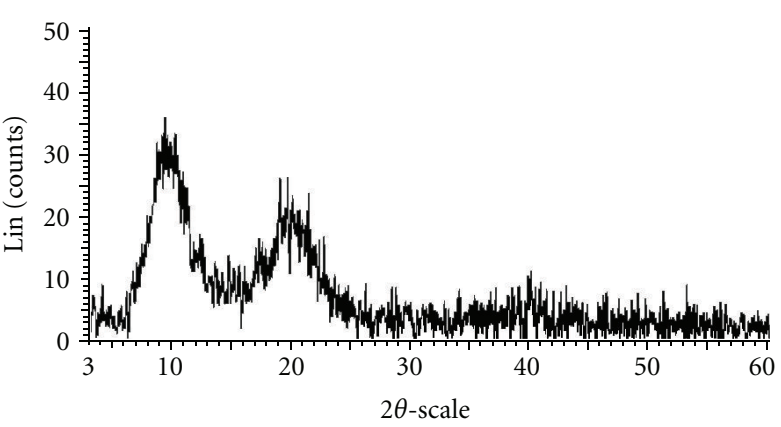

FiguRE 3: X-ray powder diffractogram of the chitosan catalyst.

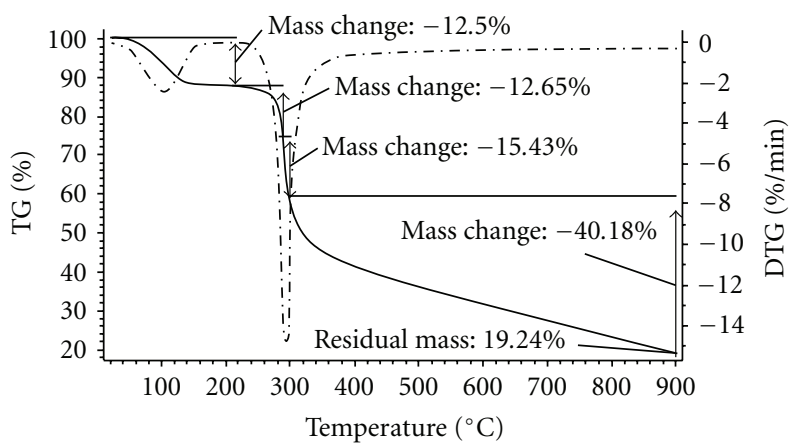

FIgURe 4: TGA analysis of the chitosan catalyst.

(Figure 2). No measurable mesoporosity was observed on the nitrogen physisorption measurements. Indeed, several approaches have been developed to achieve a porous structure for chotosan-based materials [62-66]. As inspired by green chemistry principles, unmodified chitosan was used in this research. The crystallinity of the chitosan catalyst was analyzed by XRD. Two characteristic peaks [67] at $2 \theta=10.5^{\circ}$ and $2 \theta=20.5^{\circ}$ were observed on the XRD diffractogram of the catalyst (Figure 3 ). These two broad diffraction peaks are normally considered as typical fingerprints of semicrystalline chitosan [68]. TGA result indicated that the chitosan catalyst degraded in two stages during the heating process from 30 to $900^{\circ} \mathrm{C}$ in air. The first weight loss of $12.5 \%$ was due to the residual and physisorbed water. The second step started at around $260^{\circ} \mathrm{C}$, with a decomposition peak temperature of around $300^{\circ} \mathrm{C}$ and a total weight loss of $68 \%$ (Figure 4). The thermal stability of the chitosan catalyst was, therefore, in good agreement with the literature [69], ensuring that the catalyst could be used across a wide temperature range for liquid-phase reactions.

As expected, the FT-IR spectra of the catalyst indicated characteristic bands of chitosan. Broad peaks near $3450 \mathrm{~cm}^{-1}$ were attributed to the $\mathrm{O}-\mathrm{H}$ stretching vibration of the hydroxyl groups, as well as the inter- and extramolecular hydrogen bonding of chitosan molecules [70]. These broad bands were also indicative of the presence of physisorbed water in the material. There would also exist the contribution of the $-\mathrm{NH}_{2}$ group for the band in the region of 3000$3400 \mathrm{~cm}^{-1}$, which was overlapped by the $\mathrm{O}-\mathrm{H}$ stretching vibration. The weak band near $2922 \mathrm{~cm}^{-1}$ was attributed to 


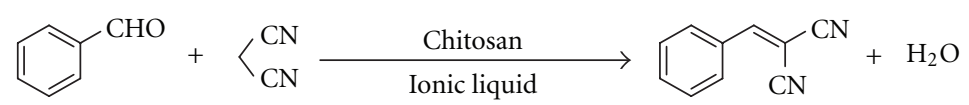

Scheme 1: Knoevenagel reaction of benzaldehyde with malononitrile using the chitosan catalyst.

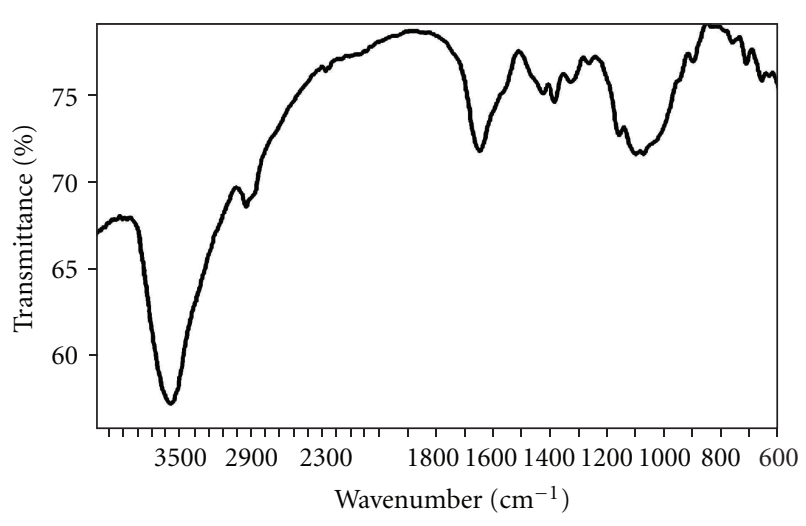

FIGURE 5: FT-IR spectra of the chitosan catalyst.

the $\mathrm{C}-\mathrm{H}$ stretching vibration. The band near $1646 \mathrm{~cm}^{-1}$ was assigned to the vibration of amide one groups (Figure 5). Elemental analysis of the catalyst indicated a total nitrogen loading of $5.2 \mathrm{mmol} / \mathrm{g}$. The degree of $\mathrm{N}$-deacetylation of the chitosan (i.e., the average number of D-glucosamine units per 100 monomers, expressed as a percentage) was found to be $87 \%$, as estimated following Block's method [71]. The amino group loading in the chitosan catalyst was therefore calculated to be $4.5 \mathrm{mmol} / \mathrm{g}$. For the reason of simplicity, the amino group loading was used as an elemental tag for the catalyst. However, it should be noted that not all of these amino groups were accessible to the reactants during the course of the reaction.

3.2. Catalytic Studies. The chitosan catalyst was assessed for its activity in the Knoevenagel condensation between benzaldehyde and malononitrile to form benzylidene malononitrile as the principal product (Scheme 1). As inspired by green chemistry principles, it was decided to carry out the reaction in the $[\mathrm{BMIM}]\left[\mathrm{PF}_{6}\right]$ ionic liquid as solvent at room temperature. The ionic liquid solvent was synthesized and characterized according to a literature procedure [60, 61]. Aliquots were withdrawn from the reaction mixture at different time intervals and analyzed by GC, showing the kinetic data during the course of the reaction. When investigating the chitosan-catalyzed Knoevenagel reaction in ionic liquid, there would be several factors that should be taken into consideration. Initial studies addressed the effect of the benzaldehyde: malononitrile molar ratio on reaction conversions, having carried out the reaction at $20 \mathrm{~mol} \% \mathrm{chi}-$ tosan catalyst with molar ratios of $1: 2,1: 3$, and $1: 4$, respectively. It was found that the Knoevenagel reaction using the reagent molar ratio of $1: 3$ could afford a conversion of $98 \%$ after $6 \mathrm{~h}$. More than $99 \%$ conversion was achieved after $3 \mathrm{~h}$ at the reagent ratio of $1: 4$. As expected, decreasing the reagent

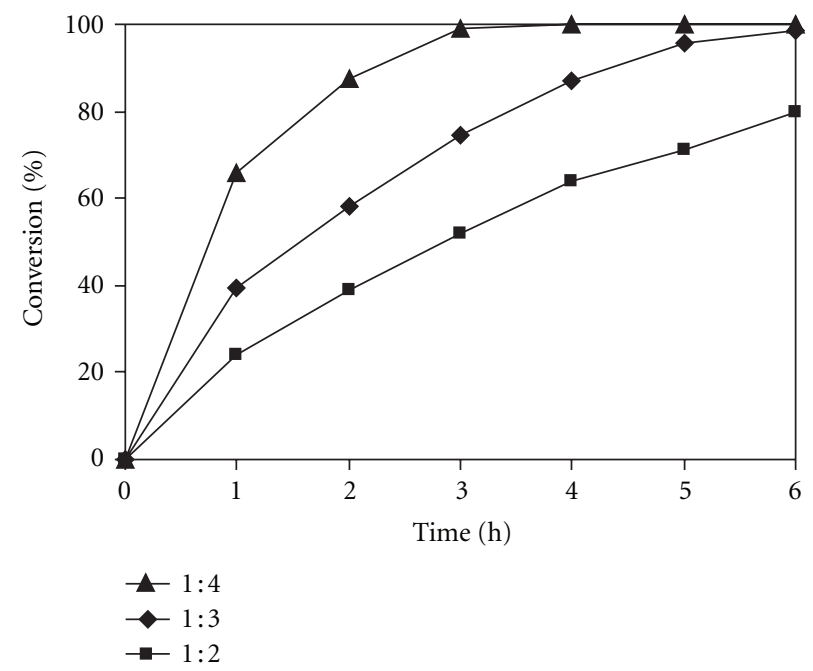

FIGURE 6: Effect of benzaldehyde: malononitrile molar ratio on reaction conversion.

molar ratio to $1: 2$ resulted in a drop in reaction rate, though $80 \%$ conversion was still observed after $6 \mathrm{~h}$ (Figure 6 ).

With this result in mind, it was then decided to investigate the effect of catalyst concentration on the reaction conversion, having carried out the reaction at $10 \mathrm{~mol} \%$, $15 \mathrm{~mol} \%$, and $20 \mathrm{~mol} \%$ catalyst, respectively, at the reagent molar ratio of $1: 4$. As mentioned earlier, the chitosan catalyst had a nonporous structure, and, therefore, not all of amino groups in the polymer chain were accessible to the reactants during the course of the reaction. Indeed, further investigations would be needed to quantify the real active amino groups in the Knoevenagel reaction carried out in ionic liquid. However, for the reason of simplicity, the amino group concentration calculated from the total nitrogen loading and the degree of $\mathrm{N}$-deacetylation was still used as an elemental tag for the chitosan catalyst. It was observed that quantitative conversion of benzaldehyde was achieved after $6 \mathrm{~h}$ for the reaction using $15 \mathrm{~mol} \%$ catalyst. As expected, it was observed that increasing the catalyst concentration to $20 \mathrm{~mol} \%$ led to a significant reaction rate enhancement, with more than 99\% conversion being obtained after $3 \mathrm{~h}$. The Knoevenagel reaction at $10 \mathrm{~mol} \%$ catalyst concentration occurred with slower rate, though $88 \%$ conversion was still afforded after $6 \mathrm{~h}$ (Figure 7). Formentin and co-workers previously employed more than one equivalent of $\mathrm{KOH}$ catalyst for the homogeneous Knoevenagel reaction between benzaldehyde and malononitrile carried out in ionic liquid [72]. Tojo and coworkers previously employed $20 \mathrm{~mol} \%$ glycine as a homogeneous catalyst for the Knoevenagel reaction in ionic liquid [73]. Indeed, it was previously reported that concentration of base catalysts used for the Knoevenagel reaction 


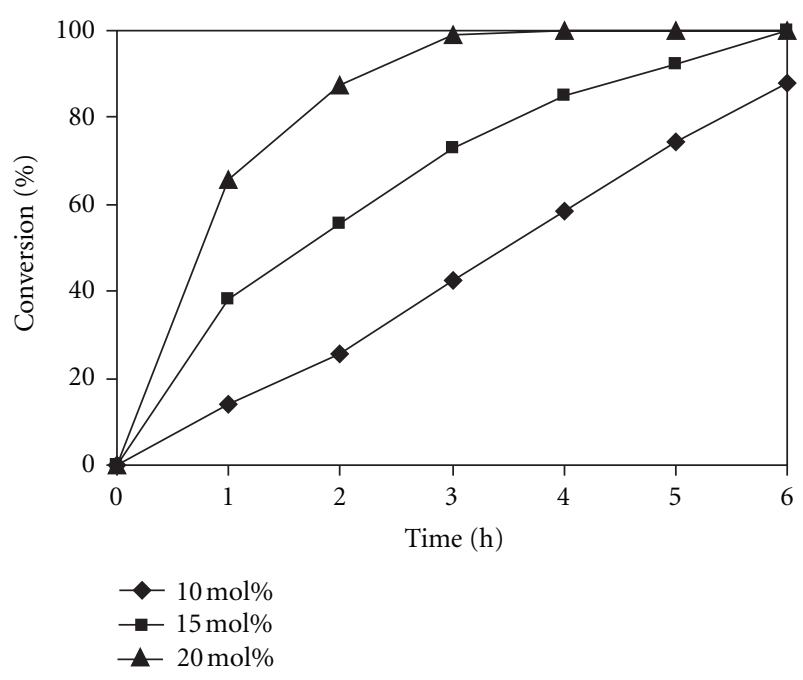

FIGURE 7: Effect of catalyst concentration on reaction conversion.

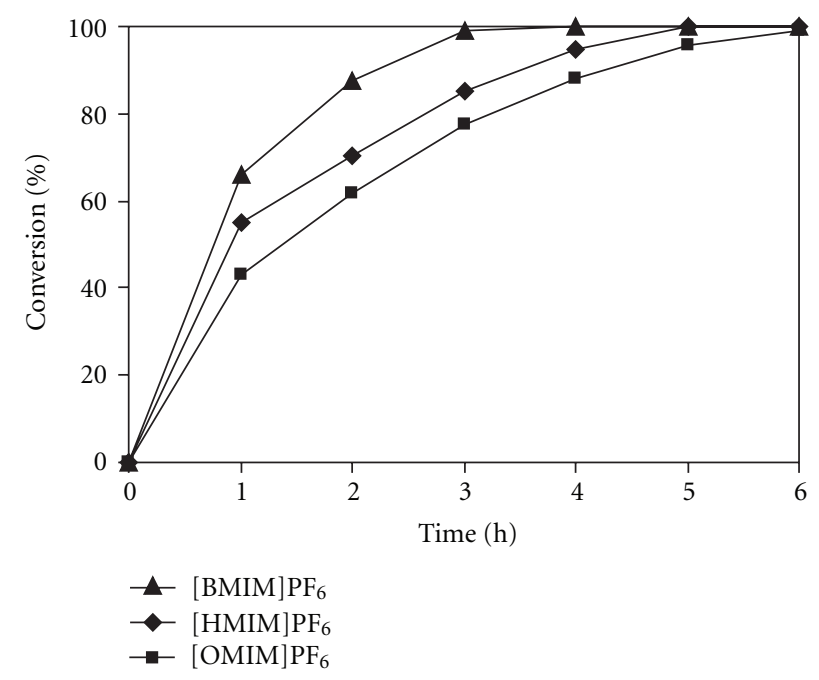

Figure 8: Effect of solvent on reaction conversion. could be in the range from less than $1 \mathrm{~mol} \%$ to $40 \mathrm{~mol} \%$, depending on the nature of the catalyst $[43,44,74,75]$. The catalyst concentration used in this study was, therefore, in good agreement with the literature.

The effect of different solvents on organic transformations using heterogeneous catalysts could normally be crucial, depending on the nature of the catalyst material $[50,76]$. Macquarrie and Jakson previously reported that the Knoevenagel reaction using silica-based catalysts could only proceed in a limited range of solvents, and the best reaction rate was observed in nonpolar solvents [77]. In contrast, Corma and coworkers previously showed that the reaction rate of the Knoevenagel reaction using solid catalysts decreased significantly in nonpolar solvents, and higher conversions were achieved in more polar solvents [7880]. Gascon and coworkers reported similar effect, where polar solvents favored the reaction rate of the heterogeneous Knoevenagel condensation, and the reaction occurred with difficulty in nonpolar solvents $[52,81]$. Dong and coworkers also demonstrated that the Knoevenagel reaction using a polymer-based catalyst proceeded readily in ethanol [82]. It was, therefore, decided to investigate the effect of different ionic liquid solvents on the Knoevenagel reaction using the chitosan catalyst. The reaction was carried out using $20 \mathrm{~mol} \%$ catalyst in there ionic liquids, including $[\mathrm{BMIM}]\left[\mathrm{PF}_{6}\right],[\mathrm{HMIM}]\left[\mathrm{PF}_{6}\right]$, and $[\mathrm{OMIM}]\left[\mathrm{PF}_{6}\right]$, respectively. It was found that the reaction rate decreased with the solvent order: $[\mathrm{BMIM}]\left[\mathrm{PF}_{6}\right]>[\mathrm{HMIM}]\left[\mathrm{PF}_{6}\right]>$ $[\mathrm{OMIM}]\left[\mathrm{PF}_{6}\right]$. The reaction carried out in $[\mathrm{HMIM}]\left[\mathrm{PF}_{6}\right]$ afforded more than $99 \%$ conversion after $5 \mathrm{~h}$, while $99 \%$ conversion was observed for the reaction in $[\mathrm{OMIM}]\left[\mathrm{PF}_{6}\right]$ (Figure 8).

For a liquid-phase organic transformation using a solid catalyst, an important problem that should be taken into account is the possibility that some of active sites could dissolve into the solution during the course of the reaction. In fact, these leached species might contribute significantly to the catalytic reaction, and the reaction might not be truly heterogeneous with respect to the substrates and products. [50]. It should be noted that several amines previously exhibited high activity in the Knoevenagel reaction [83]. However, it was apparent that these homogeneous catalysts could not be recycled and reused for the reaction, and, therefore, they were practically undesirable. In order to determine if the Knoevenagel reaction using the chitosan catalyst in ionic liquid was truly heterogeneous, an experiment was performed using a simple centrifugation during the course of the reaction. After the chitosan catalyst was separated from the reaction mixture, if the catalytic reaction continued, this would indicate that the active species were from the solution rather than from the solid catalyst. The organic phase was separated from the solid catalyst after $0.5 \mathrm{~h}$ reaction time by simple centrifugation, having used $20 \mathrm{~mol} \%$ of fresh chitosan catalyst. The reaction solution was then transferred to a new reactor vessel, stirred for an additional $5.5 \mathrm{~h}$ at room temperature with aliquots being sampled at different time intervals, and analyzed by GC. It was found that, within experimental errors, no further reaction was observed after the solid chitosan catalyst was removed from the reaction mixture. The leaching test result indicated that the Knoevenagel reaction carried out in ionic liquid could only proceed in the presence of the solid chitosan catalyst, and there was no contribution from active species dissolved in the reaction solution during the course of the reaction (Figure 9).

When using solid catalysts for organic transformations, issues that should be considered are the ease of separation as well as the deactivation and reusability of the catalyst. In fact, active lifetimes should be an important characteristic for both heterogeneous and homogeneous catalysts. Ionic liquids have been considered as green solvents not only due to their nonvolatile nature, minimizing emission of toxic organic compounds, but also because of their recyclability. The chitosan catalyst and the ionic liquid solvent were, therefore, investigated for recoverability and reusability in the Knoevenagel reaction over five successive runs. The Knoevenagel reaction was carried out using $20 \mathrm{~mol} \%$ 


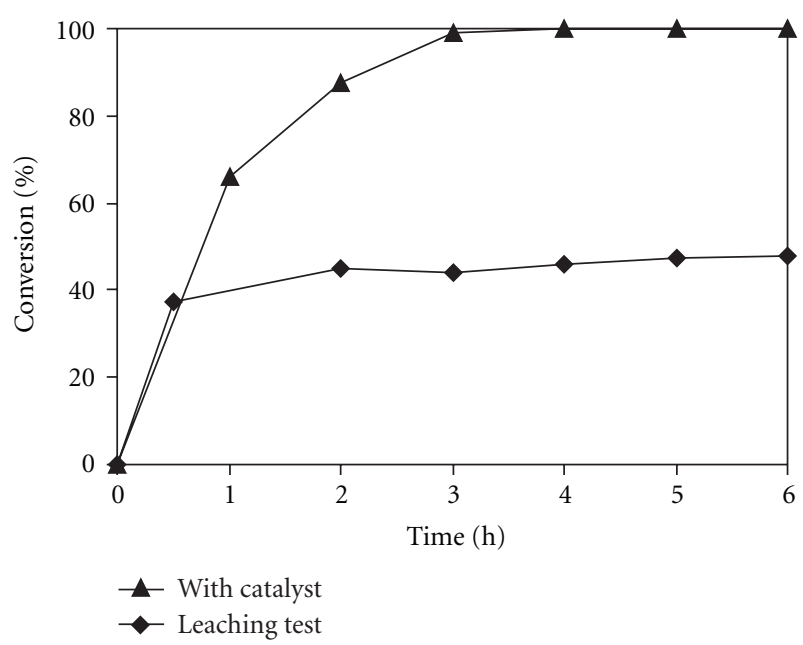

FIGURE 9: Leaching test indicated no contribution from homogeneous catalysis of active species leaching into reaction solution.

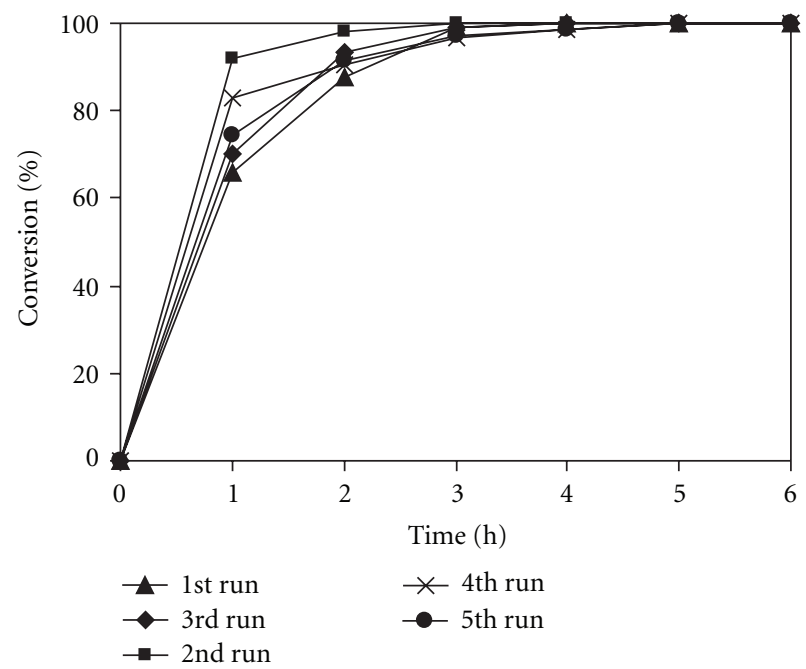

FIGURE 10: Recycling of both chitosan catalyst and ionic liquid solvent.

chitosan catalyst in the $[\mathrm{BMIM}]\left[\mathrm{PF}_{6}\right]$ ionic liquid at room temperature. Aliquots were withdrawn from the reaction mixture at different time intervals and analyzed by GC to observe the kinetic data during the course of the reaction. After the reaction, product and unreacted starting materials were separated from the reaction mixture by extraction with diethyl ether. The mixture of chitosan catalyst and ionic liquid solvent was then washed several times with diethyl ether and reused in further reaction under identical conditions to those of the first run. Interestingly, it was found that the catalyst and solvent system could be reused without significant degradation in catalytic activity. Quantitative reaction conversion was still achieved at the fifth run using the recovered catalyst and solvent system (Figure 10).

As mentioned earlier, research works have been mostly focused on homogeneous catalysis in ionic liquids, and the number of reports covering the heterogeneous catalysis in

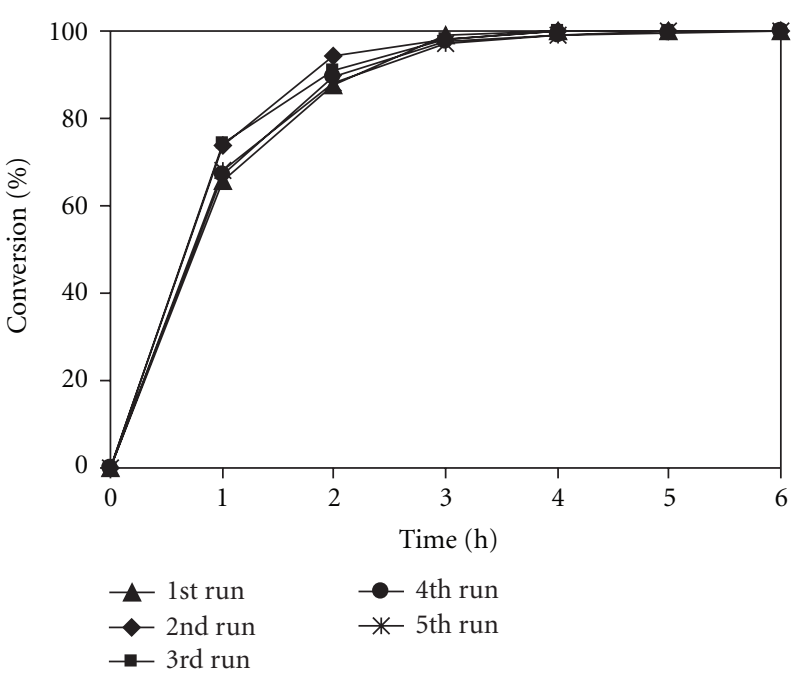

FIGURE 11: Recycling of the chitosan catalyst with fresh ionic liquid solvent for each run.

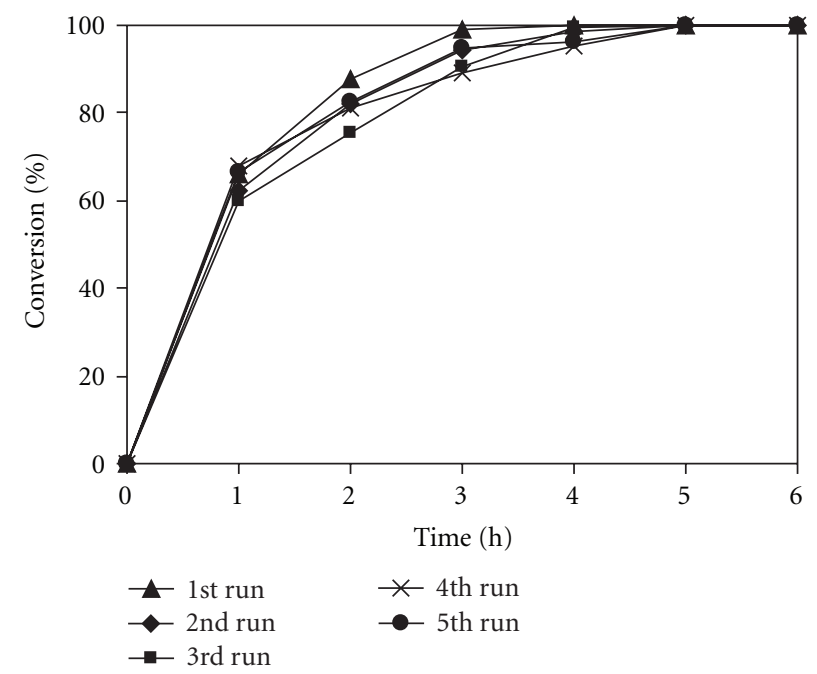

FIGURE 12: Recycling of the ionic liquid solvent with fresh chitosan catalyst for each run.

ionic liquids are limited in the literature. Santamarta and coworkers previously carried out the Knoevenagel reaction using $20 \mathrm{~mol} \%$ glycine as a homogeneous catalyst in ionic liquid [73]. The mixture of glycine and ionic liquid could be recycled and reused several times. Formentin and coworkers also reported the recyclability of the mixture of $\mathrm{KOH}$ and ionic liquid in the Knoevenagel reaction [72]. Indeed, it was previously reported that the mixture of homogeneous catalysts and ionic liquid solvents could be recycled and reused in several organic transformations [3, 6-8]. However, it should be emphasized that the homogeneous catalyst could not be separated from the mixture, and hence it could not be recovered in essentially pure form after being used in the reaction. We, therefore, decided to investigate the recovery of the chitosan catalyst from the reaction mixture, and its 
reusability in the ionic liquid-mediated Knoevenagel reaction. After the reaction, the catalyst was separated by simple centrifugation, then washed with copious amounts of anhydrous ethanol to remove any physisorbed reagents, and dried at $60^{\circ} \mathrm{C}$ overnight. The recovered chitosan catalyst was reused in further reaction using fresh ionic liquid solvent for each run under identical conditions to those of the first run. It was found that the catalyst could be reused without significant degradation in activity (Figure 11). The recovery and recyclability of the ionic liquid were also investigated. After each run, the catalyst was separated by simple centrifugation, and the ionic liquid was washed several times with diethyl ether to remove the product and unreacted starting materials. The recovered ionic liquid was then reused in further reaction using fresh chitosan catalyst for each run under identical conditions to those of the first run. It was also observed that the ionic liquid could be reused without loss of efficiency (Figure 12).

\section{Conclusions}

In conclusion, we have demonstrated the application of chitosan as a renewable solid catalyst for the Knoevenagel condensation between benzaldehyde with malononitrile to form benzylidene malononitrile as the principal product. The chitosan catalyst was characterized using a variety of different techniques, including FT-IR, TEM, SEM, XRD, TGA, and elemental analysis. The reaction was carried out in ionic liquid as a "green" solvent. Excellent conversions were achieved under mild conditions without the need for an inert atmosphere. The reaction could only proceed in the presence of the solid chitosan catalyst, and there was no contribution from leached active species in the reaction solution. To the best of our knowledge, the combination of chitosan as a renewable heterogeneous catalyst and ionic liquid as a "green" solvent for the Knoevenagel reaction was not previously mentioned in the literature. The chitosan catalyst as well as the ionic liquid solvent could be recovered in essentially pure form after being used in the reaction, and they could be reused several times without a significant degradation in efficiency. Current research in our laboratory has focused on the application of several heterogeneous catalysts for a wide range of organic transformations in ionic liquids.

\section{References}

[1] C. Chiappe, P. Piccioli, and D. Pieraccini, "Selective Nalkylation of anilines in ionic liquids," Green Chemistry, vol. 8, no. 3, pp. 277-281, 2006.

[2] R. A. Sheldon, "Green solvents for sustainable organic synthesis: state of the art," Green Chemistry, vol. 7, no. 5, pp. 267-278, 2005.

[3] V. I. Pârvulescu and C. Hardacre, "Catalysis in ionic liquids," Chemical Reviews, vol. 107, no. 6, pp. 2615-2665, 2007.

[4] K. Binnemans, "Lanthanides and actinides in ionic liquids," Chemical Reviews, vol. 107, no. 6, pp. 2592-2614, 2007.

[5] N. Jain, A. Kumar, S. Chauhan, and S. M. S. Chauhan, "Chemical and biochemical transformations in ionic liquids," Tetrahedron, vol. 61, no. 5, pp. 1015-1060, 2005.
[6] S. Baj, A. Chrobok, and S. Derfla, "A new method for dialkyl peroxides synthesis in ionic liquids as solvents," Green Chemistry, vol. 8, no. 3, pp. 292-295, 2006.

[7] Y. Y. Wang, M. M. Luo, Q. Lin, H. Chen, and X. J. Li, "Efficient biphasic hydroaminomethylation of long chain olefins in ionic liquids," Green Chemistry, vol. 8, no. 6, pp. 545-548, 2006.

[8] R. Hart, P. Pollet, D. J. Hahne et al., "Benign coupling of reactions and separations with reversible ionic liquids," Tetrahedron, vol. 66, no. 5, pp. 1082-1090, 2010.

[9] B. C. Ranu and S. S. Dey, "Catalysis by ionic liquid: a simple, green and efficient procedure for the Michael addition of thiols and thiophosphate to conjugated alkenes in ionic liquid, [pmIm]Br," Tetrahedron, vol. 60, no. 19, pp. 4183-4188, 2004.

[10] X. Yuan, N. Yan, C. Xiao et al., "Highly selective hydrogenation of aromatic chloronitro compounds to aromatic chloroamines with ionic-liquid-like copolymer stabilized platinum nanocatalysts in ionic liquids," Green Chemistry, vol. 12, no. 2, pp. 228233, 2010.

[11] A. Chrobok, "The Baeyer-Villiger oxidation of ketones with Oxone in the presence of ionic liquids as solvents," Tetrahedron, vol. 66, no. 32, pp. 6212-6216, 2010.

[12] X. Fan, Y. Wang, Y. He, X. Zhang, and J. Wang, "Ru(III)catalyzed oxidative reaction in ionic liquid: an efficient and practical route to 2 -substituted benzothiazoles and their hybrids with pyrimidine nucleoside," Tetrahedron Letters, vol. 51, no. 27, pp. 3493-3496, 2010.

[13] Y. L. Hu, Q. F. Liu, T. T. Lu, and M. Lu, "Highly efficient oxidation of organic halides to aldehydes and ketones with $\mathrm{H}_{5} \mathrm{IO}_{6}$ in ionic liquid $\left[\mathrm{C}_{12} \mathrm{mim}\right]\left[\mathrm{FeCl}_{4}\right]$," Catalysis Communications, vol. 11, no. 10, pp. 923-927, 2010.

[14] S. Gago, S. S. Balula, S. Figueiredo et al., "Catalytic olefin epoxidation with cationic molybdenum(VI) cis-dioxo complexes and ionic liquids," Applied Catalysis A, vol. 372, no. 1, pp. 6772, 2010.

[15] Z. D. Petroviæ, D. Simijonoviæ, V. P. Petroviæ, and S. Markoviæ, "Diethanolamine and N,N-diethylethanolamine ionic liquids as precatalyst-precursors and reaction media in green Heck reaction protocol," Journal of Molecular Catalysis A, vol. 327, no. 1-2, pp. 45-50, 2010.

[16] J. C. Cárdenas, L. Fadini, and C. A. Sierra, "Triphenylphosphite and ionic liquids: positive effects in the Heck crosscoupling reaction," Tetrahedron Letters, vol. 51, no. 52, pp. 6867-6870, 2010.

[17] M. V. Escárcega-Bobadilla, E. Teuma, A. M. Masdeu-Bultó, and M. Gómez, "New bicyclic phosphorous ligands: synthesis, structure and catalytic applications in ionic liquids," Tetrahedron, vol. 67, no. 2, pp. 421-428, 2011.

[18] V. Singh, R. Ratti, and S. Kaur, "Synthesis and characterization of recyclable and recoverable MMT-clay exchanged ammonium tagged carbapalladacycle catalyst for Mizoroki-Heck and Sonogashira reactions in ionic liquid media," Journal of Molecular Catalysis A, vol. 334, no. 1-2, pp. 13-19, 2011.

[19] O. Bortolini, A. De Nino, A. Garofalo, L. Maiuolo, A. Procopio, and B. Russo, "Erbium triflate in ionic liquids: a recyclable system of improving selectivity in Diels-Alder reactions," Applied Catalysis A, vol. 372, no. 2, pp. 124-129, 2010.

[20] S. S. Khan, J. Shah, and J. Liebscher, "Synthesis of new ionicliquid-tagged organocatalysts and their application in stereoselective direct aldol reactions," Tetrahedron, vol. 66, no. 27-28, pp. 5082-5088, 2010.

[21] V. Conte, G. Fiorani, B. Floris, P. Galloni, and S. Woodward, "Palladium-catalysed methylation of aryl halides in ionic liquids with stabilized $\mathrm{AlMe}_{3}$," Applied Catalysis A, vol. 381, no. 1-2, pp. 161-168, 2010. 
[22] D. J. Hong, D. W. Kim, and D. Y. Chi, "Facile ring-closure cyclization of arenes by nucleophilic C-alkylation reaction in ionic liquid," Tetrahedron Letters, vol. 51, no. 1, pp. 54-56, 2010.

[23] X. Nie, X. Liu, L. Gao, M. Liu, C. Song, and X. Guo, " $\mathrm{SO}_{3} \mathrm{H}-$ functionalized ionic liquid catalyzed alkylation of catechol with tert -Butyl alcohol," Industrial and Engineering Chemistry Research, vol. 49, no. 17, pp. 8157-8163, 2010.

[24] X. Liang and C. Qi, "Synthesis of a novel ionic liquid with both Lewis and Brønsted acid sites and its catalytic activities," Catalysis Communications, vol. 12, no. 9, pp. 808-812, 2011.

[25] H. Guo, X. Li, J. L. Wang, X. H. Jin, and X. F. Lin, "Acidic ionic liquid $[\mathrm{NMP}] \mathrm{H}_{2} \mathrm{PO}_{4}$ as dual solvent-catalyst for synthesis of $\beta$-alkoxyketones by the oxa-Michael addition reactions," Tetrahedron, vol. 66, no. 42, pp. 8300-8303, 2010.

[26] M. A. Epishina, A. S. Kulikov, N. V. Ignat'Ev, M. Schulte, and N. N. Makhova, "The first example of the Schmidt reaction in ionic liquids," Mendeleev Communications, vol. 20, no. 6, pp. 335-336, 2010.

[27] S. Muthusamy and D. Azhagan, "Efficient synthesis of 19-31 membered macrocyclic tetralactones via ring closing metathesis in ionic liquids," Tetrahedron, vol. 66, no. 41, pp. 81968202, 2010.

[28] X.-W. Peng, J.-L. Ren, and R.-C. Sun, "Homogeneous esterification of xylan-rich hemicelluloses with maleic anhydride in ionic liquid," Biomacromolecules, vol. 11, no. 12, pp. 35193524, 2010.

[29] H. Shi, W. Zhu, H. Li et al., "Microwave-accelerated esterification of salicylic acid using Brönsted acidic ionic liquids as catalysts," Catalysis Communications, vol. 11, no. 7, pp. 588$591,2010$.

[30] M. Moniruzzaman, K. Nakashima, N. Kamiya, and M. Goto, "Recent advances of enzymatic reactions in ionic liquids," Biochemical Engineering Journal, vol. 48, no. 3, pp. 295-314, 2010.

[31] K.-P. Zhang, J. Q. Lai, Z.-L. Huang, and Z. Yang, "Penicillium expansum lipase-catalyzed production of biodiesel in ionic liquids," Bioresource Technology, vol. 102, no. 3, pp. 2767-2772, 2011.

[32] Z. Yang, K.-P. Zhang, Y. Huang, and Z. Wang, "Both hydrolytic and transesterification activities of Penicillium expansum lipase are significantly enhanced in ionic liquid [BMIm] $\left[\mathrm{PF}_{6}\right]$," Journal of Molecular Catalysis B, vol. 63, no. 1-2, pp. 23-30, 2010.

[33] A. Kurata, S. Takemoto, T. Fujita, K. Iwai, M. Furusawa, and N. Kishimoto, "Synthesis of 3-cyclohexylpropyl caffeate from 5-caffeoylquinic acid with consecutive enzymatic conversions in ionic liquid," Journal of Molecular Catalysis B, vol. 69, no. 3-4, pp. 161-167, 2011.

[34] H. Watanabe, "The study of factors influencing the depolymerisation of cellulose using a solid catalyst in ionic liquids," Carbohydrate Polymers, vol. 80, no. 4, pp. 1168-1171, 2010.

[35] H.-Y. Shen, Z. M. A. Judeh, C. B. Ching, and Q.-H. Xia, "Comparative studies on alkylation of phenol with tert-butyl alcohol in the presence of liquid or solid acid catalysts in ionic liquids," Journal of Molecular Catalysis A, vol. 212, no. 1-2, pp. 301-308, 2004.

[36] Z. Zhang and Z. K. Zhao, "Solid acid and microwave-assisted hydrolysis of cellulose in ionic liquid," Carbohydrate Research, vol. 344, no. 15, pp. 2069-2072, 2009.

[37] R. Saladino, R. Bernini, V. Neri, and C. Crestini, "A novel and efficient catalytic epoxidation of monoterpenes by homogeneous and heterogeneous methyltrioxorhenium in ionic liquids," Applied Catalysis A, vol. 360, no. 2, pp. 171-176, 2009.
[38] G. Bianchini, M. Crucianelli, F. D. Angelis, V. Neri, and R. Saladino, "Highly efficient C-H insertion reactions of hydrogen peroxide catalyzed by homogeneous and heterogeneous methyltrioxorhenium systems in ionic liquids," Tetrahedron Letters, vol. 46, no. 14, pp. 2427-2432, 2005.

[39] F. Freeman, "Properties and reactions of ylidenemalononitriles," Chemical Reviews, vol. 80, no. 4, pp. 329-350, 1980.

[40] L. F. Tietze, "Domino reactions in organic synthesis," Chemical Reviews, vol. 96, no. 1, pp. 115-136, 1996.

[41] D. B. Jackson, D. J. Macquarrie, and J. H. Clark, "Organic modification of hexagonal mesoporous silicas," in Proceedings of the 4th International Symposium on Supported Reagents and Catalysts in Chemistry, 2001.

[42] L. Martins, K. M. Vieira, L. M. Rios, and D. Cardoso, "Basic catalyzed Knoevenagel condensation by FAU zeolites exchanged with alkylammonium cations," Catalysis Today, vol. 133-135, no. 1-4, pp. 706-710, 2008.

[43] K. M. Parida, S. Mallick, P. C. Sahoo, and S. K. Rana, "A facile method for synthesis of amine-functionalized mesoporous zirconia and its catalytic evaluation in Knoevenagel condensation," Applied Catalysis A, vol. 381, no. 1-2, pp. 226-232, 2010.

[44] B. Karmakar, B. Chowdhury, and J. Banerji, "Mesoporous titanosilicate Ti-TUD-1 catalyzed Knoevenagel reaction: an efficient green synthesis of trisubstituted electrophilic olefins," Catalysis Communications, vol. 11, no. 7, pp. 601-605, 2010.

[45] F. Shang, J. Sun, S. Wu, Y. Yang, Q. Kan, and J. Guan, "Direct synthesis of acid-base bifunctional mesoporous MCM-41 silica and its catalytic reactivity in Deacetalization-Knoevenagel reactions," Microporous and Mesoporous Materials, vol. 134, no. 1-3, pp. 44-50, 2010.

[46] K. M. Parida and D. Rath, "Amine functionalized MCM-41: an active and reusable catalyst for Knoevenagel condensation reaction," Journal of Molecular Catalysis A, vol. 310, no. 1-2, pp. 93-100, 2009.

[47] L. Martins, W. Hölderich, P. Hammer, and D. Cardoso, "Preparation of different basic Si-MCM-41 catalysts and application in the Knoevenagel and Claisen-Schmidt condensation reactions," Journal of Catalysis, vol. 271, no. 2, pp. 220$227,2010$.

[48] F. Shang, J. Sun, S. Wu, Y. Yang, Q. Kan, and J. Guan, "Direct synthesis of acid-base bifunctional mesoporous MCM-41 silica and its catalytic reactivity in Deacetalization-Knoevenagel reactions," Microporous and Mesoporous Materials, vol. 134, no. 1-3, pp. 44-50, 2010.

[49] G. Postole, B. Chowdhury, B. Karmakar, K. Pinki, J. Banerji, and A. Auroux, "Knoevenagel condensation reaction over acid-base bifunctional nanocrystalline $\mathrm{CexZr}_{1-x} \mathrm{O}_{2}$ solid solutions," Journal of Catalysis, vol. 269, no. 1, pp. 110-121, 2010.

[50] N. T. S. Phan and C. W. Jones, "Highly accessible catalytic sites on recyclable organosilane-functionalized magnetic nanoparticles: an alternative to functionalized porous silica catalysts," Journal of Molecular Catalysis A, vol. 253, no. 1-2, pp. 123-131, 2006.

[51] M. Trilla, R. Pleixats, M. W. C. Man, and C. Bied, "Organicinorganic hybrid silica materials containing imidazolium and dihydroimidazolium salts as recyclable organocatalysts for Knoevenagel condensations," Green Chemistry, vol. 11, no. 11, pp. 1815-1820, 2009.

[52] J. Gascon, U. Aktay, M. D. Hernandez-Alonso, G. P. M. van Klink, and F. Kapteijn, "Amino-based metal-organic frameworks as stable, highly active basic catalysts," Journal of Catalysis, vol. 261, no. 1, pp. 75-87, 2009.

[53] U. P. N. Tran, K. K. A. Le, and N. T. S. Phan, "Expanding 
applications of metal-organic frameworks: zeolite imidazolate framework ZIF-8 as an efficient heterogeneous catalyst for the knoevenagel reaction," ACS Catalysis, vol. 1, no. 2, pp. 120 $127,2011$.

[54] M. J. Gronnow, R. Luque, D. J. Macquarrie, and J. H. Clark, "A novel highly active biomaterial supported palladium catalyst," Green Chemistry, vol. 7, no. 7, pp. 552-557, 2005.

[55] S. E. S. Leonhardt, A. Stolle, B. Ondruschka et al., "Chitosan as a support for heterogeneous Pd catalysts in liquid phase catalysis," Applied Catalysis A, vol. 379, no. 1-2, pp. 30-37, 2010.

[56] K. Martina, S. E. S. Leonhardt, B. Ondruschka, M. Curini, A. Binello, and G. Cravotto, "In situ cross-linked chitosan $\mathrm{Cu}(\mathrm{I})$ or $\mathrm{Pd}(\mathrm{II})$ complexes as a versatile, eco-friendly recyclable solid catalyst," Journal of Molecular Catalysis A, vol. 334, no. 1-2, pp. 60-64, 2011.

[57] B. C. E. Makhubela, A. Jardine, and G. S. Smith, "Pd nanosized particles supported on chitosan and 6-deoxy-6-amino chitosan as recyclable catalysts for Suzuki-Miyaura and Heck cross-coupling reactions," Applied Catalysis A, vol. 393, no. 12, pp. 231-241, 2010.

[58] T. C. O. Mac Leod, V. Palaretti, V. P. Barros, A. L. Faria, T. A. Silva, and M. D. Assis, "Jacobsen catalyst immobilized on chitosan membrane as interface catalyst in organic/aqueous system for alkene oxidation," Applied Catalysis A, vol. 361, no. 1-2, pp. 152-159, 2009.

[59] N. Sudheesh, S. K. Sharma, and R. S. Shukla, "Chitosan as an eco-friendly solid base catalyst for the solvent-free synthesis of jasminaldehyde," Journal of Molecular Catalysis A, vol. 321, no. 1-2, pp. 77-82, 2010.

[60] R. S. Varma and V. V. Namboodiri, "An expeditious solventfree route to ionic liquids using microwaves," Chemical Communications, vol. 7, pp. 643-644, 2001.

[61] J. G. Huddleston, H. D. Willauer, R. P. Swatloski, A. E. Visser, and R. D. Rogers, "Room temperature ionic liquids as novel media for "clean" liquid-liquid extraction," Chemical Communications, no. 16, pp. 1765-1766, 1998.

[62] R. Valentin, K. Molvinger, F. Quignard, and D. Brunel, "Supercritical $\mathrm{CO}_{2}$ dried chitosan: an efficient intrinsic heterogeneous catalyst in fine chemistry," New Journal of Chemistry, vol. 27, no. 12, pp. 1690-1692, 2003.

[63] Z. Liu, H. Bai, and D. D. Sun, "Facile fabrication of porous chitosan $/ \mathrm{TiO}_{2} / \mathrm{Fe}_{3} \mathrm{O}_{4}$ microspheres with multifunction for water purifications," New Journal of Chemistry, vol. 35, no. 1, pp. 137-140, 2011.

[64] C. Lau, M. J. Cooney, and P. Atanassov, "Conductive macroporous composite chitosan-carbon nanotube scaffolds," Langmuir, vol. 24, no. 13, pp. 7004-7010, 2008.

[65] A. El Kadib, K. Molvinger, C. Guimon, F. Quignard, and D. Brunel, "Design of stable nanoporous hybrid chitosan/titania as cooperative bifunctional catalysts," Chemistry of Materials, vol. 20, no. 6, pp. 2198-2204, 2008.

[66] Y. Kanai, T. Oshima, and Y. Baba, "Synthesis of highly porous chitosan microspheres anchored with 1,2-ethylenedisulfide moiety for the recovery of precious metal ions," Industrial \& Engineering Chemistry Research, vol. 47, no. 9, pp. 3114-3120, 2008.

[67] B. Kang, Y. D. Dai, H. Q. Zhang, and D. Chen, "Synergetic degradation of chitosan with gamma radiation and hydrogen peroxide," Polymer Degradation and Stability, vol. 92, no. 3, pp. 359-362, 2007.

[68] C. Bangyekan, D. Aht-Ong, and K. Srikulkit, "Preparation and properties evaluation of chitosan-coated cassava starch films," Carbohydrate Polymers, vol. 63, no. 1, pp. 61-71, 2006.
[69] B. Klaykruayat, K. Siralertmukul, and K. Srikulkit, "Chemical modification of chitosan with cationic hyperbranched dendritic polyamidoamine and its antimicrobial activity on cotton fabric," Carbohydrate Polymers, vol. 80, no. 1, pp. 197207, 2010 .

[70] G. Ma, D. Yang, Y. Zhou, M. Xiao, J. F. Kennedy, and J. Nie, "Preparation and characterization of water-soluble N-alkylated chitosan," Carbohydrate Polymers, vol. 74, no. 1, pp. 121$126,2008$.

[71] S. Sabnis and L. H. Block, "Improved infrared spectroscopic method for the analysis of degree of N-deacetylation of chitosan," Polymer Bulletin, vol. 39, no. 1, pp. 67-71, 1997.

[72] P. Formentín, H. García, and A. Leyva, "Assessment of the suitability of imidazolium ionic liquids as reaction medium for base-catalysed reactions: case of Knoevenagel and ClaisenSchmidt reactions," Journal of Molecular Catalysis A, vol. 214, no. 1, pp. 137-142, 2004.

[73] F. Santamarta, P. Verdía, and E. Tojo, "A simple, efficient and green procedure for Knoevenagel reaction in $[\mathrm{MMIm}]\left[\mathrm{MSO}_{4}\right]$ ionic liquid," Catalysis Communications, vol. 9, no. 8, pp. 1779-1781, 2008.

[74] Y. Kubota, Y. Nishizaki, H. Ikeya et al., "Organic-silicate hybrid catalysts based on various defined structures for Knoevenagel condensation," Microporous and Mesoporous Materials, vol. 70, no. 1-3, pp. 135-149, 2004.

[75] Y. Liu, J. Liang, X. H. Liu, J. C. Fan, and Z. C. Shang, "Polyethylene glycol (PEG) as a benign solvent for Knoevenagel condensation," Chinese Chemical Letters, vol. 19, no. 9, pp. 1043-1046, 2008.

[76] G. Langhendries, D. E. De Vos, G. V. Baron, and P. A. Jacobs, "Quantitative sorption experiments on Ti-zeolites and relation with $\alpha$-olefin oxidation by $\mathrm{H}_{2} \mathrm{O}_{2}$," Journal of Catalysis, vol. 187, no. 2, pp. 453-463, 1999.

[77] D. J. Macquarrie and D. B. Jackson, "Aminopropylated MCMs as base catalysts: a comparison with aminopropylated silica," Chemical Communications, no. 18, pp. 1781-1782, 1997.

[78] I. Rodriguez, G. Sastre, A. Corma, and S. Iborra, "Catalytic activity of proton sponge: application to knoevenagel condensation reactions," Journal of Catalysis, vol. 183, no. 1, pp. 1423, 1999.

[79] A. Corma, S. Iborra, I. Rodriguez, and F. Sanchez, "Immobilized proton sponge on inorganic carriers the synergic effect of the support on catalytic activity," Journal of Catalysis, vol. 211, no. 1, pp. 208-215, 2002.

[80] M. J. Climent, A. Corma, I. Domínguez, S. Iborra, M. J. Sabater, and G. Sastre, "Gem-diamines as highly active organocatalysts for carbon-carbon bond formation," Journal of Catalysis, vol. 246, no. 1, pp. 136-146, 2007.

[81] J. Juan-Alcañiz, E. V. Ramos-Fernandez, U. Lafont, J. Gascon, and F. Kapteijn, "Building MOF bottles around phosphotungstic acid ships: one-pot synthesis of bi-functional polyoxometalate-MIL-101 catalysts," Journal of Catalysis, vol. 269, no. 1, pp. 229-241, 2010.

[82] F. Dong, Y. Q. Li, and R. F. Dai, "Knoevenagel condensation catalysed by poly(vinyl chloride) supported tetraethylenepentamine (PVC-TEPA)," Chinese Chemical Letters, vol. 18, no. 3, pp. 266-268, 2007.

[83] A. Pande, K. Ganesan, A. K. Jain, P. K. Gupta, and R. C. Malhotra, "A novel eco-friendly process for the synthesis of 2chlorobenzylidenemalononitrile and its analogues using water as a solvent," Organic Process Research and Development, vol. 9, no. 2, pp. 133-136, 2005. 


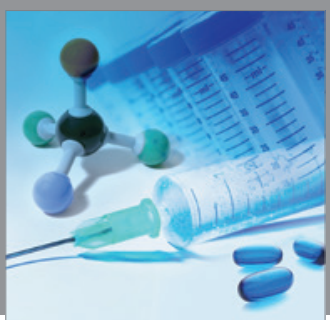

International Journal of

Medicinal Chemistry

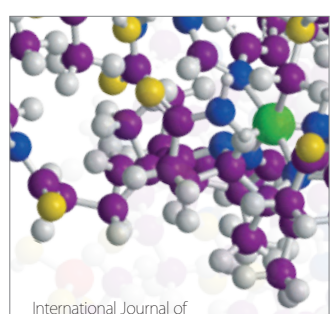

Carbohydrate Chemistry

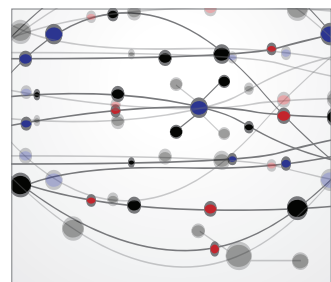

The Scientific World Journal
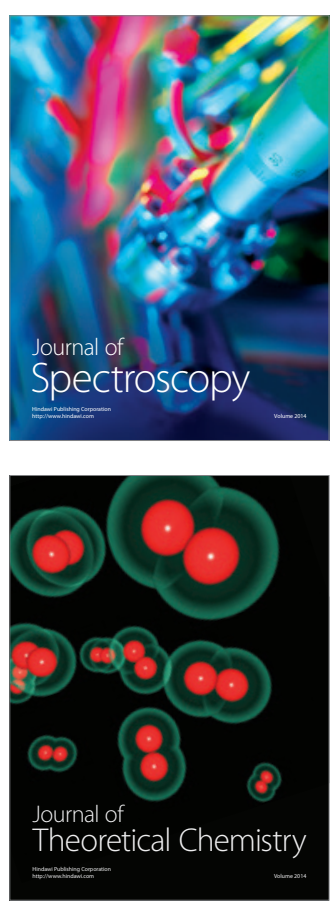
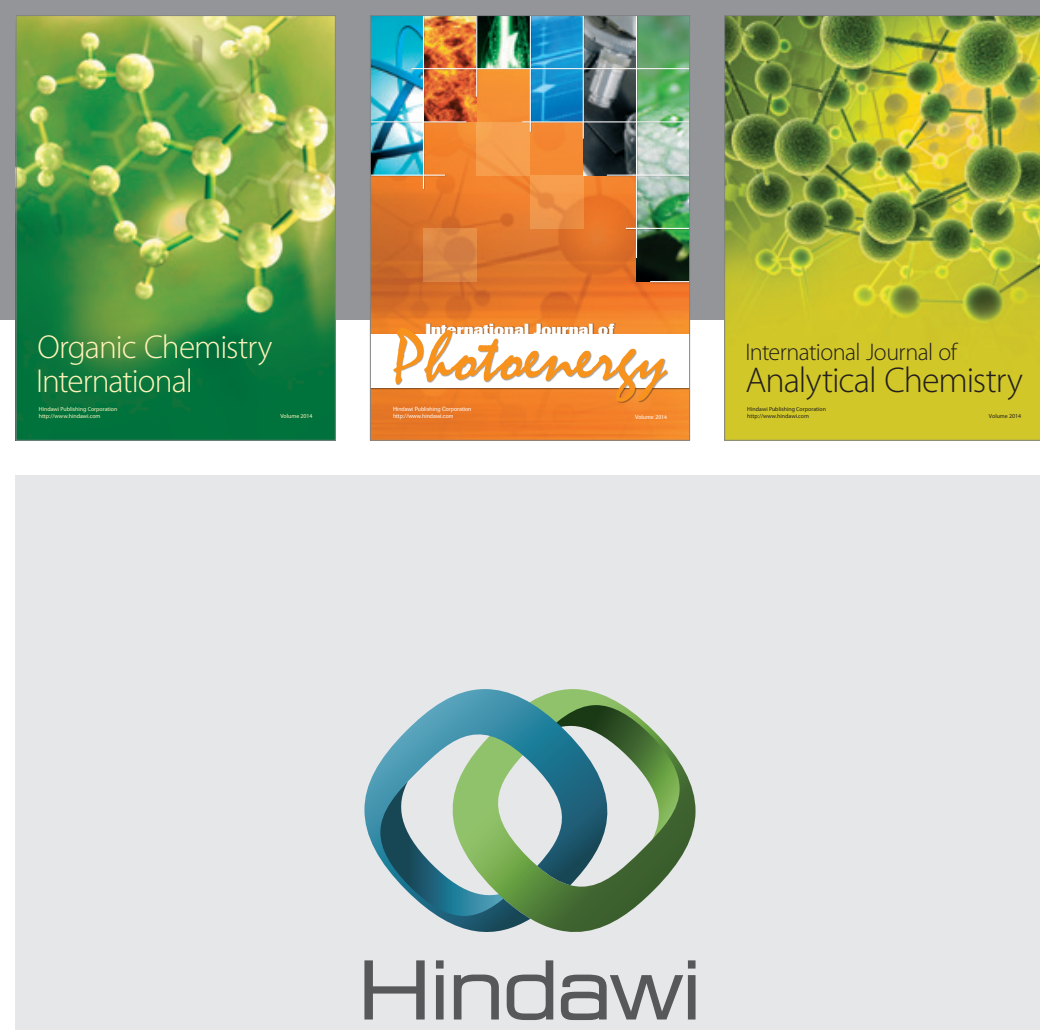

Submit your manuscripts at

http://www.hindawi.com
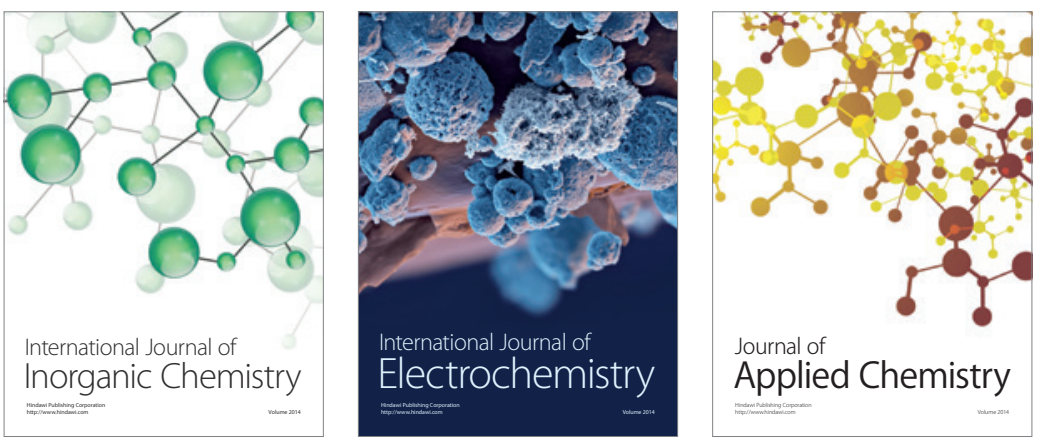

Journal of

Applied Chemistry
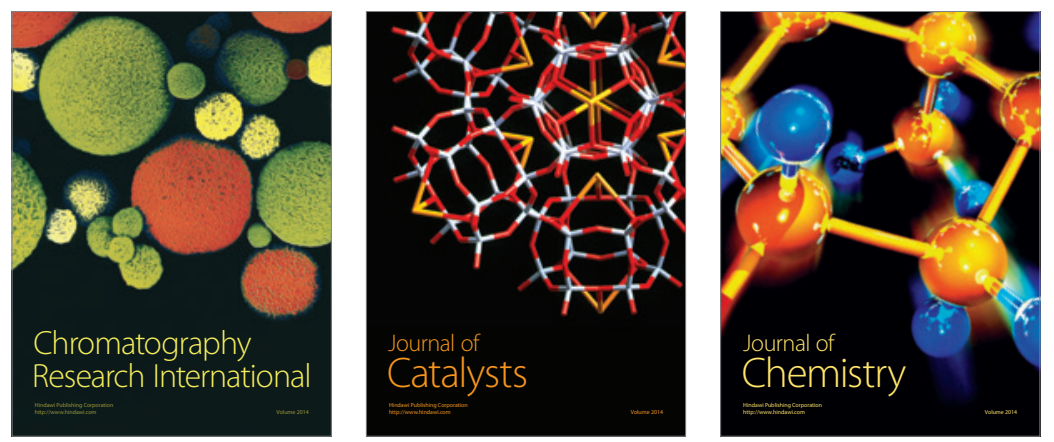
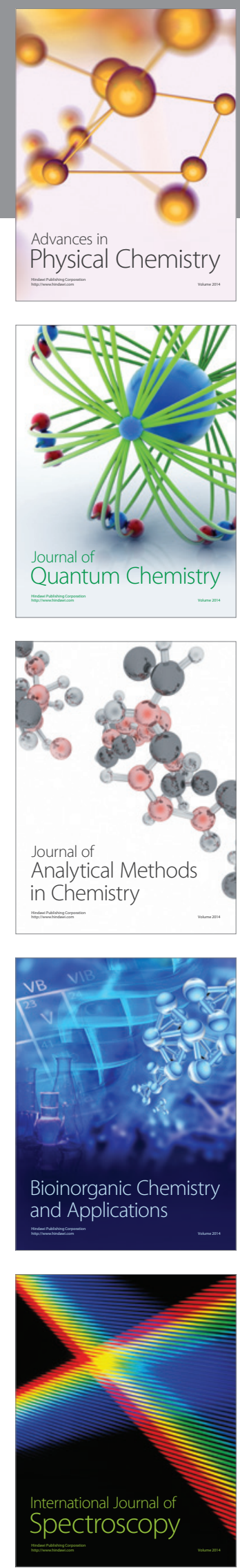